\title{
Roles of p63 in Epidermal Development and Tumorigenesis
}

\author{
Jeng-Yuan Yao, Jan-Kan Chen
}

\begin{abstract}
Epidermis is composed mainly of keratinocytes and is the major barrier of human body. The development and maintenance of normal epithelial structures and functions require the transcription factor p63. The p63 gene encodes proteins with structures similar to that of p53, including an N-terminal transactivation (TA) domain, a DNA-binding domain and a carboxy-oligomerization domain. TAp63 and $\Delta$ Np63 (p63 isoforms without TA domain) regulate a wide range of target genes that are important for embryonal development and epithelial integrity. Mutations of p63 gene cause epidermal abnormalities characterized by ectodermal dysplasia. Recent reports have indicated that $\mathrm{p} 63$ plays important role in tumorigenesis as well. However, the relative importance of TAp63 and $\Delta \mathrm{Np63}$ in epidermal development and tumorigenesis remains mostly unclear and awaits further investigation. In this review, we summarize the current knowledge on the structure and function of p63 and its isoforms. (Biomed J 2012;35:457-63)
\end{abstract}

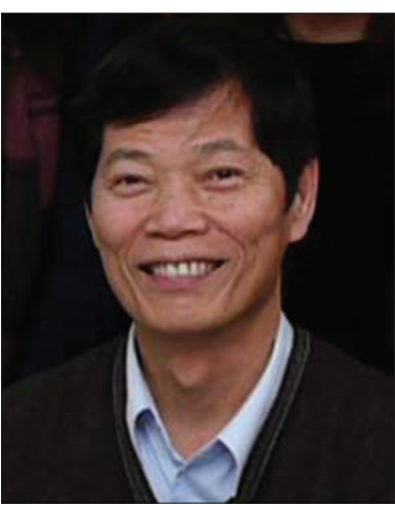

Prof. Jan-Kan Chen

\section{Key words: keratinocytes, p53, TAp63}

$\mathrm{T}$ he human p63 gene is located on chromosome $3 q 27$ and composed of 15 exons spanning more than 250 $\mathrm{kb} .{ }^{[1]}$ The $\mathrm{p} 63$ gene contains two promoters, alternative promoter usage and $\mathrm{C}$-terminal splicing generate two groups of three isoforms named TAp63, $\beta, \gamma$ and Np63, $\beta, \gamma$ [Figure 1(A)]. ${ }^{[2]}$ The TAp63 isoforms contain the $\mathrm{N}$-terminal transactivation (TA) domain and are capable of transactivating target genes. In contrast, the Np63 isoforms lack the TA domain and are believed to act as negative regulators of the TAp63 function. ${ }^{[3]}$ Both p63 and p53 genes encode proteins with similar functional domains, high degrees of sequence homologies, and are suggested to regulate common target genes [Figure 1(B)]. The $\mathrm{p} 63 \alpha$ protein contains an additional sterile alpha motif (SAM) domain that is not found in $\mathrm{p} 53$, it is a proteinprotein interaction domain believed to be involved in the developmental processes. ${ }^{[4,5]}$ Because of the sequential similarities, TAp63 proteins are able to bind and transactivate many p53 target genes; ${ }^{[6]}$ however, many studies indicated that TAp63 proteins can bind DNA through responsive elements related to p63 but not p53. ${ }^{[7-9]}$ Because of the lack of TA domain, $\Delta \mathrm{Np} 63$ was reported to block p53 or TAp63-mediated transactivation. ${ }^{[2]}$ Moreover,
$\Delta \mathrm{Np} 63$ has subsequently been demonstrated to transactivate their own target genes rather than just a dominant negative regulator over TAp63 and p53. ${ }^{[10-12]}$ The functions of distinct p63 isoforms have not been defined, both TAp63 and $\triangle$ Np63 mRNA were found to be present in mouse embryos and mature epithelia; however, the $\Delta \mathrm{Np} 63$ protein level is much higher than TAp63 in most of the postdevelopmental tissues. ${ }^{[13,14]}$ In contrast, TAp63 is more strongly expressed in oocytes than $\Delta \mathrm{Np} 63$, implying their different regulatory roles during development. ${ }^{[15,16]}$

\section{p63 in embryonic epithelia}

p63 is expressed in the ectodermal surfaces of the limb buds, branchial arches and epidermal appendages in mouse embryo. ${ }^{[17]}$ The function of p63 in epithelial development was first observed in p63-/- mice. p63-null mice were born alive but soon died of dehydration due to severe defects in the development of stratified epithelial barrier. ${ }^{[17,18]}$ Reintroduction of TAp63 $\alpha$ in p63-/- mice showed only limited areas of epithelialization, whereas reintroduction of $\Delta \mathrm{Np} 63 \alpha$ showed better epithelialization, although still with limited epidermal basal layer formation.${ }^{[19]}$ Other major defects in p63-/- mice include truncated limbs and deformed

From the Department of Physiology, College of Medicine, Chang Gung University, Taoyuan, Taiwan.

Received: Mar. 6, 2012; Accepted: May 23, 2012

Correspondence to: Prof. Jan-Kan Chen, Department of Physiology, College of Medicine, Chang Gung University. 259 Wen-Hwa $1^{\text {st }}$ Road, Kweishan, Taoyuan 333, Taiwan (R.O.C.). Tel: 886-3-2118800 ext. 5077; Fax: 886-3-2118700; E-mail: jkc508@ mail.cgu.edu.tw 


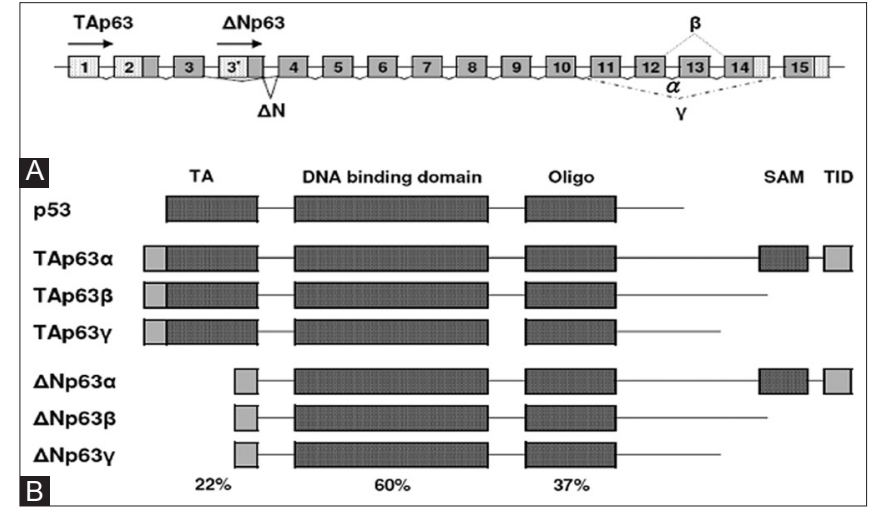

Figure 1: (A) Structure of p63 gene. The alternative promoter usage drives the expression of TAp63 (with transactivation domain) and Np63 (without transactivation domain) isoforms. In addition, alternative splicing at the 3 end gives rise to 3 different $\mathrm{p} 63$ variants $(\alpha, \beta$ and $\gamma)$. (B) Schematic presentations of the protein domains of p53 and p63. p53 and p63 share homologous protein domains, including a transactivation domain, a DNA-binding domain and an oligomerization domain. The forms of p63 variants possess a C-terminal SAM domain followed by a transactivational inhibitory domain (TID).

craniofacial structures. ${ }^{[17,18]}$ The skin of p63-negative mice was not stratified, did not express differentiation markers and was arrested in its early developmental stage. ${ }^{[18]}$ p63-negative mice were also found to lack the structures associated with epidermal-mesenchymal interactions during embryonic development, ${ }^{[18,20]}$ the epidermis were found to undergo nonregenerative differentiation, leading to the absence of all squamous epithelia and their derivatives, including mammary, lacrymal and salivary glands. ${ }^{[17]}$ Later study showed that TAp63 was the first p63 isoforms expressed during mouse embryogenesis and was required for the initiation of epithelial stratification program and the inhibition of terminal differentiation. ${ }^{[21]}$ In the contrary, $\Delta$ Np63 counteracted TAp63 function and promoted the maturation of embryonic epidermis. ${ }^{[21]}$ In accordance with the above observations, disruption of $\Delta \mathrm{Np} 63$ expression in zebrafish was found to result in the failure of epidermal morphogenesis and fin truncations. ${ }^{[22,23]}$ At the molecular level, $\Delta \mathrm{Np} 63$ has been shown to regulate genes characteristic of the epidermal basal layer (K14) and TAp63 regulate genes characteristic of the superbasal layer's (Ets-1, K1, transglutaminases, involucrin). ${ }^{[19]}$ In addition, $\Delta$ Np63 was suggested to integrate multiple signaling pathways required for the tooth and hair placodes formation by regulating Bmp-7, Fgfr2b, jag1, Notch1 expression. In turn, $\Delta$ Np63 expression was promoted by BMP2, BMP7 and FGF10. ${ }^{[24]}$ In addition, p63 was also suggested to regulate the cell proliferation and differentiation of tooth germ epithelial cells. ${ }^{[25]}$ Taken together, $\mathrm{p} 63$ appeared to be required for the maintenance of certain progenitor cell populations that are necessary for epithelial turn over and development, while

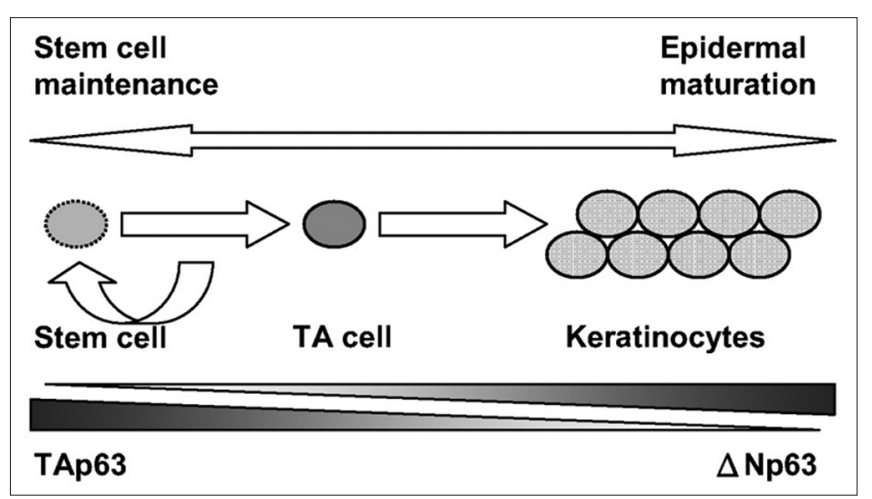

Figure 2: TAp63 and Np63 exert different roles during epidermal development. TAp63 isoforms are firstly expressed in the uncommitted ectoderm and act as a key switch to initiate epithelial stratification. Np63 isoforms are expressed after the ectoderm has committed for epithelial stratification.

$\Delta$ Np63 promoted TA cell conversion and keratinocyte terminal differentiation [Figure 2].

\section{p63 in adult epithelia}

The corneal epithelium exhibits high level of cellular turn over under normal physiology and in wound healing. Corneal epithelial cells are driven from limbal epithelial stem cells, a special population of progenitor cells located in the basal layer of the corneoscleral limbus. In the corneolimbal surface, p63 was found to be expressed in the basal layer of the limbal epithelium but not in the cornea, ${ }^{[26,27]}$ suggesting a role of p63 in limbal stem cell maintenance and differentiation. The successful reconstruction of limbal deficient eyes with cultured limbal epithelial cells, ${ }^{[28]}$ and the observation that a higher percentage of the p63-positive cell in the prosthesis led to a higher successful reconstruction rate strongly supported the above notion. ${ }^{[29]}$ However, the expression patterns of p63 and other keratinocyte stem cell markers in rat cornea appeared to be differed from that of human and rabbit. In an earlier report, we found that the expression of p63 in rat cornea was altered with age. In the neonates, p63-positive cells were present in limbus, peripheral cornea and central cornea. In 1-month-old rats, they were present in central and peripheral cornea, but not in limbus, and in adult rats (6 month and older), the p63positive cells were present only in the peripheral cornea. ${ }^{[30,31]}$ In rabbits, the expression pattern was obviously different, we found that the expression of TAp63 was expressed at the highest level in limbus, decreased in peripheral cornea by approximately 10-fold and was undetectable in the central cornea. Rather similarly, $\Delta \mathrm{Np} 63$ was also expressed at the highest level in limbus, decreased by approximately $35 \%$ in peripheral cornea, and was undetectable in the central cornea. ${ }^{[32]}$ The expression of these proteins exhibited clear effect in the limbal explant cultures, we showed that 
knockdown of TAp63 expression inhibited the proliferation but promoted the differentiation of cultured rabbit limbal keratinocytes. Knockdown of $\Delta \mathrm{Np} 63$ expression also inhibited cell proliferation, however, exerted no obvious effect on cell differentiation. ${ }^{[32]}$ Recently, we showed KGF is a potent growth stimulator for the epithelial outgrowth from limbal explants and the stimulation was dependent on p38-mediated $\Delta \mathrm{Np} 63 \alpha$ expression. ${ }^{[33]}$ Stimulation of limbal epithelial outgrowth by KGF was significantly reduced by knockdown of $\Delta \mathrm{Np} 63 \alpha$, strongly supported a role of $\Delta \mathrm{Np} 63 \alpha$ in the regulation of limbal epithelial cell proliferation and differentiation.

Taken together, TAp63 and $\Delta \mathrm{Np} 63$ appeared to play distinct roles in regulating proliferation and differentiation of the limbal epithelial cells, and were probably required for the maintenance of the limbal and corneal epithelial integrity.

\section{p63 as a transcription factor}

The functions of distinct p63 isoforms have not been clearly elucidated. Although both TAp63 and $\Delta$ Np63 transcripts were found in mouse embryo and mature epithelia, the $\Delta \mathrm{Np} 63$ protein level was shown to be much higher than TAp63 in most of the postdevelopmental tissues. ${ }^{[13,14]}$ In contrast, TAp63 was shown to be strongly expressed in oocytes. ${ }^{[15,16]}$

Due to isoform diversity, intensive studies have focused on examining the signaling pathways regulated by p63 and on genes that may be activated or repressed. Since p 63 and p53 proteins are structurally highly homologous with very similar DNA-binding domains. ${ }^{[2,34]}$ the initial studies were focused on whether p63 regulates p53 target genes. In this regard, TAp63 has been suggested to transactivate p53responsive genes, whereas $\Delta \mathrm{Np} 63$ acts in a dominant negative manner ${ }^{[2]}$ Recently, a transcriptional inhibitory domain (TID) located between the SAM domain and the C-terminus has been identified in $\mathrm{p} 63 \alpha$ and was shown to mediate the repressive effects of $\mathrm{p} 63 \alpha$ variants. ${ }^{[35]}$ The C-terminus of TAp63 $\alpha$ proteins is proposed to interact with the TA domain to prevent its binding to coactivator proteins. ${ }^{[35]}$ This was supported by the report shown that TAp63 $\gamma$ stimulates the transcription of p53 responsive gene, whereas TAp63 $\alpha$ showed little transactivation activity. In addition, $\Delta \mathrm{Np} 63 \alpha$ was reported to repress the transcription activity of p53 and TAp63, but $\Delta$ Np63 $\gamma$ could only repress the transcription activity of $\mathrm{p} 53 .^{[2]}$ Another study demonstrated that TAp63 binds directly to the p53-responsive genes, including mdm2, bax, PERP and NOXA, suggesting possible functional overlaps of TAp63 and p53 in regulating the genome stability and apoptotic functions of the $\mathrm{p} 53 .^{[36,37]}$

Transient transfection of cells with TAp63 variants has been reported to induce both cell cycle arrest and apoptosis..$^{[2,38,39]}$ These studies showed that TAp63 $\gamma$ variant exhibited the greatest transactivation activity, in contrast, TAp63 $\alpha$ exhibit less or no activity. A similar study confirmed that $\Delta \mathrm{Np} 63$ variants exhibited opposite effects on cell cycle regulation and apoptosis compared to that generated by TAp63 variants. ${ }^{[2]}$ Loss of TAp63 has been shown to result in failure of p53 expressing cells to undergo apoptosis in response to DNA damage, ${ }^{[36]}$ suggesting the involvement of p63 in regulating cell fate under genotoxicity. In contrast, p53 knockout mice exhibited no developmental epithelial disorders, suggests a distinctive regulatory function from that of p63. Further studies to delineate the exact roles of six p63 variants in keratinocyte differentiation and proliferation is still yet to come. ${ }^{[40]} \Delta \mathrm{Np} 63 \alpha$ has also been reported to act as a transcriptional repressor required for ventral specification in the ectoderm of gastrulating embryos. ${ }^{[22]}$ It could also repressed the gene transcription through fusing with the yeast transcription factor Gal4 ${ }^{[41]}$ suggesting a unique regulatory mechanism independent of its promoter binding activity.

\section{Regulation of p63 stability and activity}

The expression of TAp63 in normal tissue is highly restricted and has rarely been reported. Recently, TATAbinding protein-like protein (TLP), a protein regulates stressmediated cell cycle checkpoint and apoptotic pathways, was shown to upregulate the transcriptional activity of TAp63. ${ }^{[42]}$ However, the mechanism underlying such regulation awaits further study. The TAp63 protein stability was reported to be regulated by its transactivation domain (TA), at the amino terminal residues 50 to $69 .{ }^{\left[{ }^{[3]}\right.}$ Moreover, WWP1 E3 ubiquitin ligase was reported to bind, ubiquitinate, and destruct both $\Delta \mathrm{Np} 63 \alpha$ and TAp63 $\alpha$ through the proteasome pathway. ${ }^{[4]}$ Other studies showed that Plk1 was able to bind to TAp63 at Ser-52 of the TA domain leading to its phosphorylation, which in turn led to decreased TAp63 protein stability and TAp63-induced cell death. ${ }^{[44,45]}$ EGFR pathway has been reported to regulate the expression of $\Delta \mathrm{Np} 63 \alpha \cdot{ }^{[46]} \Delta \mathrm{Np} 63 \alpha$ expression was also regulated by the PI3K pathway and plays a critical role in the survival and proliferative capacity of the squamous epithelia. ${ }^{[47]}$ The PI3K pathway activity was reported to be implicated in a number of human diseases including diabetes and cancer. ${ }^{[48,49]}$

Our previous study showed that in NPC076 cell, $\triangle$ Np63 imposes a dual-regulatory effect on its own promoter activity. ${ }^{[50]}$ We showed that $\Delta \mathrm{Np} 63$ transcriptional activity is downregulated when $\Delta \mathrm{Np} 63$ is present in low levels. In contrast, it was upregulated when $\Delta \mathrm{Np} 63$ is expressed at higher levels. The autoregulation of $\Delta \mathrm{Np} 63$ gene transcription was mediated through activation of STAT3 and its subsequent binding to the STAT3 response element in its own promoter. ${ }^{[51]}$ We also showed that STAT3 enhances the proliferation of limbal keratinocytes through a $\Delta \mathrm{Np} 63$ dependent mechanism. ${ }^{[52]}$ 
Moreover, we also found that inhibition of glycogen synthase kinase-3beta (GSK-3beta) by lithium chloride ( $\mathrm{LiCl})$ leads to increased $\Delta \mathrm{Np} 63$ promoter activity and protein expression in HEK $293 \mathrm{~T}$ cells. ${ }^{[53]}$ We showed that GSK-3beta inhibitor stimulates $\Delta \mathrm{Np} 63$ promoter activity through beta-catenin responsive element. Beta-catenin interacted with Lef- 1 to regulate $\Delta \mathrm{Np} 63$ promoter activity and protein expression. ${ }^{[53]}$

In vivo studies showed that $\Delta \mathrm{Np} 63$ isoforms exhibited a longer half-life than TAp63 isoforms and deletion of the TA domain reduced the degradation of TAp63 protein by 26S proteasome pathway. ${ }^{[43,54]}$ The FWL motif, that was reported to be essential for $\mathrm{p} 53$ degradation, also promoted mdm2-mediated TAp63 degradation. ${ }^{[55-58]}$ Other study showed that TAp63 $\alpha$ isoform exhibited a longer half-life than TAp63 $\gamma$ isoform, and the C-terminal end appeared to play a role in their stability. ${ }^{[58]}$ The $\mathrm{C}$-terminal SAM domain in the $\alpha$ isoform was reported to protect p63 through FWL motif-mediated degradation. ${ }^{[35,59]}$ The degradation of $\Delta \mathrm{Np} 63$ was also reported to process through proteosome-dependent pathway and stratifyin (14-3-3 $\sigma$ ) and RACK1 were believed to be involved. ${ }^{[60]}$

Cellular protein species that have been reported to interact with TAp63 to stimulate TAp63 activity include ASPP1, ${ }^{[61]}$ ASPP2, ${ }^{[61]} \mathrm{PML},{ }^{[62]} \mathrm{Sp} 1,{ }^{[63]} \mathrm{SSRP} 1$ and $\mathrm{p} 300 .{ }^{[64,65]}$ These studies suggested that all p53 family members share common coactivators. Intriguingly, p14ARF was reported to activate and stabilize p53, but inhibited p63. ${ }^{[66]}$

p63 activity was also regulated by post-translational modifications. Under genotoxic stresses, some Ser/Thr residues of TAp63 $\alpha$ and $\gamma$ have been shown to be dephosphorylated leading to protein stabilization ${ }^{[54]}$ However, in Saos2 osteosarcoma cells, genotoxic stresses was shown to promote the degradation of $\Delta \mathrm{Np} 63 \alpha \cdot{ }^{[67]}$ In addition, the SUMOylation of the Np63 $\alpha$ at a single lysine reside, k637, was reported to promote the proteasome-dependent degradation. ${ }^{[68]}$ The aforementioned studies suggested multiple mechanisms are involved in the regulation of p63 stability.

\section{p63 in cancers}

Functional studies of p63 and p53 showed a close relation between developmental processes and tumorigenesis. ${ }^{[69]}$ There have been numerous studies shown that p63 plays critical roles in cell cycle arrest, DNA damage repair process and apoptosis; however, its precise role in cancer remained unclear. Yang et al., (1998) were the first to show that $\Delta \mathrm{Np} 63 \alpha$ is the primary p63 variant expressed in squamous epithelial tissues. ${ }^{[2]}$ Overexpression of p63 has been found to be a frequent event in some human cancers, including $93 \%$ of squamous cell carcinomas of the lung, $10 \%$ of ductal carcinomas of the breast and $25 \%$ of endometrioid carcinomas of the ovary. ${ }^{[70]}$ On the other hand, p63 was rarely detected in cancers developed from tissues that do not normally express p63, including breast and lung adenocarcinomas, possibly due to the lack in these tumors of the epithelial basal cells where p63 is normally expressed..$^{[40,70]}$ In addition, a recent report indicated that p63 plays important roles in the development and progression of grade I/II endometrial adenocarcinoma. ${ }^{[71]}$ It has been suggested that dysregulated expression of p63 is often correlated with amplification of its genomic locus, 3q27-28 and is frequently occurred in human epithelial cancers. ${ }^{[40]}$

Studies on a cohort of 245 esophageal tumors showed that both TAp63 and $\Delta \mathrm{Np} 63$ isoforms were upregulated at the transcriptional level in squamous cell carcinoma. ${ }^{[72]}$ $\Delta \mathrm{Np} 63 \alpha$ was identified to be expressed in squamous epithelial tissues and was believed to antagonize the tumor suppressor function of p53. ${ }^{[2]}$ Although TAp63 is functionally and structurally similar to the tumor suppressor p53, the functional role of its expression in this context has not been fully demonstrated. Numerous recent studies have suggested that TAp63 exerted different effects in carcinogenesis. For instances, loss of p63 expression was associated with poor prognosis of the bladder carcinoma ${ }^{[73]}$ and was shown to increase cell migration and expression of genes involved in tumor invasion and metastasis. ${ }^{[74]}$ Another study showed that the expression of p63 was required for p53 expressing cells to undergo apoptosis in response to DNA damage. ${ }^{[36]}$ Most recently, p63 and p53 were found to repress carcinogenesis through repressing telomerase expression. ${ }^{[75]}$ In addition, TAp63 was reported to trigger cell senescence and halt tumorigenesis irrespective of p53 expression status. ${ }^{[76]}$

Ectopic expression of $\Delta \mathrm{Np} 63 \alpha$ was reported to increase the half-life of the hypoxia inducible factor $1 \alpha(\mathrm{HIF}-1 \alpha),{ }^{[77]}$ leading to upregulation of the vascular endothelial growth factor (VEGF) due to elevated binding of HIF-1 $\alpha$ to the VEGF promoter. ${ }^{[77]} \Delta \mathrm{Np} 63 \alpha$ was also reported to interact with the $\mathrm{B} 56 \alpha \alpha$ regulatory subunit of the protein phosphatase $2 \mathrm{~A}$ and glycogen synthase kinase $3 \beta$ proteins ${ }^{[78,79]}$ that were suggested to inhibit the destruction complex of adenomatous polyposis coli. ${ }^{[78,79]}$ Inhibition of the destruction complex downregulated phosphorylated $\beta$-catenin leading to transcriptional activation of matrix metalloproteinases. ${ }^{[78,79]} \mathrm{We}$ recently found that the proliferation of NPC-076 cells was greatly suppressed when $\Delta \mathrm{Np} 63$ was silenced by specific $\Delta$ Np63 siRNA. ${ }^{[80]}$ This study also showed that knockdown of $\Delta \mathrm{Np} 63$ resulted in the upregulation of CKIs, including p27 and p57 in both mRNA and protein levels and increased G1 phase cell and apoptotic cell populations. These findings suggested that $\triangle \mathrm{Np} 63$ plays important roles in the regulation of NPC-076 cell-cycle progression, and contributes to the maintenance of NPC-076 tumor cell phenotype. 
Our previous studies also showed that the transcriptional activity of the TAp63 promoter and TAp63 protein level were both upregulated by an increased c-jun expression in Hep3B human hepatocellular carcinoma cell. ${ }^{[81]}$ The elevated TAp63 expression was coincided with an increased binding of c-jun to the TAp63 promoter. Moreover, knockdown of TAp63 expression by shRNA led to an increased proliferation of Hep3B cell compared to that of the mock cell, suggesting a growth suppressive effect of TAp63 expression ${ }^{[81]}$ Ectopic expression of p53 in p53-deficient cell (Hep3B) reduced TAp63 promoter activity and knockdown of TAp63 attenuated doxorubicin-induced cell growth arrest by promoting cell cycle progression via increasing the percentage of G2/M cells. ${ }^{[82]}$ Moreover, knockdown of TAp63 increased cell sensitivity to doxorubicin-induced genomic damage. Our results suggested that TAp63 may play a compensatory role in p53-deficient cancer cells in cell cycle regulation and DNA damage repair. ${ }^{[82]}$ Collectively, these studies suggested a tumor suppressor function for TAp63. However, in other studies, TAp63 was found to function as a proto-oncogene when it was improperly reactivated. ${ }^{[83]}$ Yen et al., showed that the expression of TAp63 in esophageal carcinoma was upregulated during early carcinogenesis and downregulated as the tumor progresses. ${ }^{[84]}$ Despite the above mentioned studies, the exact roles of p63 in tumorigenesis have been unclear.

\section{Conclusions}

High levels of p63 expression were found in the basal cells of many stratified epithelial tissues where a majority of human neoplasm develops. It is therefore suggested that p63 not only is essential for epithelial development, it may also be involved in pathological conditions, including cancer development and DNA damage repair. The balance between TAp63 and $\Delta \mathrm{Np} 63$ isoforms appears to be important in regulating cellular fates, such as maintenance of uncommitted stem cell vs. differentiation, survival vs. apoptosis, and tumorigenesis vs. tumor suppression. We suggest that understanding the roles of interplays between TAp63 and $\Delta \mathrm{Np} 63$ could probably provide useful information in ocular surface reconstruction of the limbal deficient eyes, normal epithelial development, carcinogenesis and the protective effect of p53 deficient cells under genotoxicity.

\section{REFERENCES}

1. McKeon F. p63 and the epithelial stem cell: more than status quo? Genes Dev 2004;18:465-9.

2. Yang A, Kaghad M, Wang Y, Gillett E, Fleming MD, Dotsch V, et al. p63, a p53 homolog at 3q27-29, encodes multiple products with transactivating, death-induc-ing, and dominant-negative activities. Mol Cell 1998;2:305-16.
3. Allocati N, Di IC, De Laurenzi V. p63/p73 in the control of cell cycle and cell death. Exp Cell Res 2012;318:1285-90.

4. Thanos CD, Bowie JU. p53 Family members p63 and p73 are SAM domain-containing proteins. Protein Sci 1999;8:1708-10.

5. Schultz J, Ponting CP, Hofmann K, Bork P. SAM as a protein interaction domain involved in developmental regulation. Protein Sci 1997;6:249-53.

6. Benard J, Douc-Rasy S, Ahomadegbe JC. TP53 family members and human cancers. Hum Mutat 2003;21:182-91.

7. Murray-Zmijewski F, Lane DP, Bourdon JC. p53/p63/p73 isoforms: An orchestra of isoforms to harmonise cell differentiation and response to stress. Cell Death Differ 2006;13:962-72.

8. Sasaki Y, Naishiro Y, Oshima Y, Imai K, Nakamura Y, Tokino T. Identification of pigment epithelium-derived factor as a direct target of the p53 family member genes. Oncogene 2005;24:5131-6.

9. Osada M, Park HL, Nagakawa Y, Yamashita K, Fomenkov A, Kim MS, et al. Differential recognition of response elements determines target gene specificity for p 53 and p63. Mol Cell Biol 2005;25:607789.

10. Dohn M, Zhang S, Chen X. p63alpha and DeltaNp63alpha can induce cell cycle arrest and apoptosis and differentially regulate p53 target genes. Oncogene 2001;20:3193-205.

11. Romano RA, Birkaya B, Sinha S. A functional enhancer of keratin 14 is a direct transcriptional target of deltaNp63. J Invest Dermatol 2007; $127: 1175-86$.

12. King KE, Ponnamperuma RM, Yamashita T, Tokino T, Lee LA, Young MF, et al. deltaNp63alpha functions as both a positive and a negative transcriptional regulator and blocks in vitro differentiation of murine keratinocytes. Oncogene 2003;22:3635-44.

13. Mikkola ML. p63 in skin appendage development. Cell Cycle 2007;6:285-90.

14. Koster MI, Dai D, Roop DR. Conflicting roles for p63 in skin development and carcinogenesis. Cell Cycle 2007;6:269-73.

15. Livera G, Petre-Lazar B, Guerquin MJ, Trautmann E, Coffigny H, Habert R. p63 null mutation protects mouse oocytes from radioinduced apoptosis. Reproduction 2008;135:3-12.

16. Suh EK, Yang A, Kettenbach A, Bamberger C, Michaelis AH, Zhu Z, et al. p63 protects the female germ line during meiotic arrest. Nature 2006;444:624-8.

17. Yang A, Schweitzer R, Sun D, Kaghad M, Walker N, Bronson RT, et al. p63 is essential for regenerative proliferation in limb, craniofacial and epithelial development. Nature 1999;398:714-8.

18. Mills AA, Zheng B, Wang XJ, Vogel H, Roop DR, Bradley A. p63 is a 53 homologue required for limb and epidermal morphogenesis. Nature 1999;398:708-13.

19. Candi E, Rufini A, Terrinoni A, Dinsdale D, Ranalli M, Paradisi A, et al. Differential roles of p63 isoforms in epidermal development: selective genetic complementation in p63 null mice. Cell Death Differ 2006;13:1037-47.

20. Ferguson MW. Palate development. Development 1988;103 Suppl:41-60.

21. Koster MI, Kim S, Mills AA, DeMayo FJ, Roop DR. p63 is the molecular switch for initiation of an epithelial stratification program. Genes Dev 2004;18:126-31.

22. Bakkers J, Hild M, Kramer C, Furutani-Seiki M, Hammerschmidt M. 
Zebrafish DeltaNp63 is a direct target of Bmp signaling and encodes a transcriptional repressor blocking neural specification in the ventral ectoderm. Dev Cell 2002;2:617-27.

23. Lee H, Kimelman D. A dominant-negative form of p63 is required for epidermal proliferation in zebrafish. Dev Cell 2002;2:607-16.

24. Laurikkala J, Mikkola ML, James M, Tummers M, Mills AA, Thesleff I. p63 regulates multiple signalling pathways required for ectodermal organogenesis and differentiation. Development 2006;133:1553-63.

25. Matsuura T, Kawata VK, Nagoshi H, Tomooka Y, Sasaki K, Ikawa S Regulation of proliferation and differentiation of mouse tooth germ epithelial cells by distinct isoforms of $\mathrm{p} 51 / \mathrm{p} 63$. Arch Oral Biol 2012;57:1108-15.

26. Pellegrini G, Dellambra E, Golisano O, Martinelli E, Fantozzi I, Bondanza S, et al. p63 identifies keratinocyte stem cells. Proc Natl Acad Sci U S A 2001;98:3156-61.

27. Chen Z, de Paiva CS, Luo L, Kretzer FL, Pflugfelder SC, Li DQ. Characterization of putative stem cell phenotype in human limbal epithelia. Stem Cells 2004;22:355-66.

28. Tsai RJ, Li LM, Chen JK. Reconstruction of damaged corneas by transplantation of autologous limbal epithelial cells. N Engl J Med 2000;343:86-93.

29. Rama P, Matuska S, Paganoni G, Spinelli A, De LM, Pellegrini G. Limbal stem-cell therapy and long-term corneal regeneration. N Engl J Med 2010;363:147-55.

30. Wang DY, Hsueh YJ, Yang VC, Chen JK. Propagation and phenotypic preservation of rabbit limbal epithelial cells on amniotic membrane. Invest Ophthalmol Vis Sci 2003;44:4698-704.

31. Hsueh YJ, Wang DY, Cheng CC, Chen JK. Age-related expressions of p63 and other keratinocyte stem cell markers in rat cornea. J Biomed Sci 2004;11:641-51.

32. Wang DY, Cheng CC, Kao MH, Hsueh YJ, Ma DH, Chen JK. Regulation of limbal keratinocyte proliferation and differentiation by TAp63 and DeltaNp63 transcription factors. Invest Ophthalmol Vis Sci 2005;46:3102-8.

33. Cheng CC, Wang DY, Kao MH, Chen JK. The growth-promoting effect of KGF on limbal epithelial cells is mediated by upregulation of DeltaNp63alpha through the p38 pathway. J Cell Sci 2009;122:4473-80.

34. Celli J, Duijf P, Hamel BC, Bamshad M, Kramer B, Smits AP, et al. Heterozygous germline mutations in the $\mathrm{p} 53$ homolog p63 are the cause of EEC syndrome. Cell 1999;99:143-53.

35. Serber Z, Lai HC, Yang A, Ou HD, Sigal MS, Kelly AE, et al. A C-terminal inhibitory domain controls the activity of p63 by an intramolecular mechanism. Mol Cell Biol 2002;22:8601-11.

36. Flores ER, Tsai KY, Crowley D, Sengupta S, Yang A, McKeon F, et al. p63 and $\mathrm{p} 73$ are required for $\mathrm{p} 53$-dependent apoptosis in response to DNA damage. Nature 2002;416: 560-4.

37. Cai Y, Qiu S, Gao X, Gu SZ, Liu ZJ. iASPP inhibits p53-independent apoptosis by inhibiting transcriptional activity of $\mathrm{p} 63 / \mathrm{p} 73$ on promoters of proapoptotic genes. Apoptosis. 2012;17:777-83.

38. Ishida S, Yamashita T, Nakaya U, Tokino T. Adenovirus-mediated transfer of p53-related genes induces apoptosis of human cancer cells. Jpn J Cancer Res 2000;91:174-80.

39. Osada M, Ohba M, Kawahara C, Ishioka C, Kanamaru R, Katoh I, et al. Cloning and functional analysis of human p 51 , which structurally and functionally resembles p53. Nat Med 1998;4:839-43.
40. Westfall MD, Pietenpol JA. p63: Molecular complexity in development and cancer. Carcinogenesis 2004;25:857-64.

41. Westfall MD, Mays DJ, Sniezek JC, Pietenpol JA. The Delta Np63 alpha phosphoprotein binds the p21 and 14-3-3 sigma promoters in vivo and has transcriptional repressor activity that is reduced by Hay-y-Wells syndrome-derived mutations. Mol Cell Biol 2003;23:2264-76.

42. Suenaga Y, Ozaki T, Tanaka Y, Bu Y, Kamijo T, Tokuhisa T, et al. TBP (TATA-binding Protein)-like Protein (TLP) Is engaged in etoposideinduced apoptosis through transcriptional activation of HumanTAp63 Gene. J Biol Chem 2009;284: 284:35433-40.

43. Osada $M$, Inaba $R$, Shinohara $H$, Hagiwara $M$, Nakamura M, Ikawa Y. Regulatory domain of protein stability of human P51/TAP63, a P53 homologue. Biochem Biophys Res Commun 2001;283:1135-41.

44. Li Y, Zhou Z, Chen C. WW domain-containing E3 ubiquitin protein ligase 1 targets p63 transcription factor for ubiquitin-mediated proteasomal degradation and regulates apoptosis. Cell Death Differ 2008;15:1941-51.

45. Komatsu S, Takenobu H, Ozaki T, Ando K, Koida N, Suenaga Y, et al. Plk1 regulates liver tumor cell death by phosphorylation of TAp63. Oncogene 2009;28:3631-41

46. Matheny KE, Barbieri CE, Sniezek JC, Arteaga CL, Pietenpol JA Inhibition of epidermal growth factor receptor signaling decreases p63 expression in head and neck squamous carcinoma cells. Laryngoscope 2003;113:936-9.

47. Barbieri CE, Barton CE, Pietenpol JA. Delta Np63 alpha expression is regulated by the phosphoinositide 3-kinase pathway. J Biol Chem $2003 ; 278: 51408-14$

48. Vivanco I, Sawyers CL. The phosphatidylinositol 3-Kinase AKT pathway in human cancer. Nat Rev Cancer 2002;2:489-501.

49. Cantley LC. The phosphoinositide 3-kinase pathway. Science 2002;296:1655-7.

50. Chu WK, Lee KC, Chow SE, Chen JK. Dual regulation of the DeltaNp63 transcriptional activity by DeltaNp63 in human nasopharyngeal carcinoma cell. Biochem Biophys Res Commun 2006;342:1356-60.

51. Chu WK, Dai PM, Li HL, Chen JK. Transcriptional activity of the DeltaNp63 promoter is regulated by STAT3. J Biol Chem 2008;283:7328-37.

52. Hsueh YJ, Chen HC, Chu WK, Cheng CC, Kuo PC, Lin LY, et al. STAT3 regulates the proliferation and differentiation of rabbit limbal epithelial cells via a Delta Np63- dependent mechanism. Invest Ophthalmol Vis Sci 2011;52:4685-93.

53. Chu WK, Dai PM, Li HL, Chen JK. Glycogen synthase kinase-3beta regulates DeltaNp63 gene transcription through the beta-catenin signaling pathway. J Cell Biochem 2008;105:447-53.

54. Okada Y, Osada M, Kurata S, Sato S, Aisaki K, Kageyama Y, et al. p53 gene family p51(p63)-encoded, secondary transactivator p51B(TAp63alpha) occurs without forming an immunoprecipitable complex with MDM2, but responds to genotoxic stress by accumulation. Exp Cell Res 2002;276:194-200.

55. Little NA, Jochemsen AG. Hdmx and Mdm 2 can repress transcription activation by $\mathrm{p} 53$ but not by p63. Oncogene 2001;20:4576-80.

56. Wang X, Arooz T, Siu WY, Chiu CH, Lau A, Yamashita K, et al. MDM2 and MDMX can interact differently with ARF and members of the p53 family. FEBS Lett 2001;490:202-8.

Biomed J Vol. 35 No. 6

November - December 2012 
57. Kadakia M, Slader C, Berberich SJ. Regulation of $\mathrm{p} 63$ function by Mdm2 and MdmX. DNA Cell Biol 2001;20:321-30.

58. Calabro V, Mansueto G, Parisi T, Vivo M, Calogero RA, La MG. The human MDM2 oncoprotein increases the transcriptional activity and the protein level of the p53 homolog p63. J Biol Chem 2002;277:2674-81.

59. Petitjean A, Hainaut P, Caron de FC. TP63 gene in stress response and carcinogenesis: A broader role than expected. Bull Cancer 2006;93:E126-35.

60. Fomenkov A, Zangen R, Huang YP, Osada M, Guo Z, Fomenkov T, et al. RACK1 and stratifin target DeltaNp63alpha for a proteasome degradation in head and neck squamous cell carcinoma cells upon DNA damage. Cell Cycle 2004;3:1285-95.

61. Bergamaschi D, Samuels Y, Jin B, Duraisingham S, Crook T, Lu X. ASPP1 and ASPP2: common activators of p53 family members. Mol Cell Biol 2004;24:1341-50.

62. Bernassola F, Oberst A, Melino G, Pandolfi PP. The promyelocytic leukaemia protein tumour suppressor functions as a transcriptional regulator of p63. Oncogene 2005;24: 6982-6.

63. Koutsodontis G, Vasilaki E, Chou WC, Papakosta P, Kardassis D. Physical and functional interactions between members of the tumour suppressor p53 and the Sp families of transcription factors: importance for the regulation of genes involved in cell-cycle arrest and apoptosis. Biochem J 2005;389:443-55.

64. Zeng SX, Dai MS, Keller DM, Lu H. SSRP1 functions as a co-activator of the transcriptional activator p63. EMBO J 2002;21:5487-97.

65. MacPartlin M, Zeng S, Lee H, Stauffer D, Jin Y, Thayer M, et al. p300 regulates p63 transcriptional activity. J Biol Chem 2005; 280:30604-10.

66. Calabro V, Mansueto G, Santoro R, Gentilella A, Pollice A, Ghioni P, et al. Inhibition of $\mathrm{p} 63$ transcriptional activity by p14ARF: Functional and physical link between human ARF tumor suppressor and a member of the p53 family. Mol Cell Biol 2004;24:8529-40.

67. Westfall MD, Joyner AS, Barbieri CE, Livingstone M, Pietenpol JA. Ultraviolet radiation induces phosphorylation and ubiquitin-mediated degradation of Delta Np63al-pha. Cell Cycle 2005;4:710-6.

68. Ghioni P, D'Alessandra Y, Mansueto G, Jaffray E, Hay RT, La MG, et al. The protein stability and transcriptional activity of p63alpha are regulated by SUMO-1 conjugation. Cell Cycle 2005;4:183-90.

69. Zaika AI, El-Rifai W. The role of $\mathrm{p} 53$ protein family in gastrointestinal malignancies. Cell Death Differ 2006;13:935-40.

70. Reis-Filho JS, Simpson PT, Martins A, Preto A, Gartner F, Schmitt FC. Distribution of p63, cytokeratins $5 / 6$ and cytokeratin 14 in 51 normal and 400 neoplastic human tissue samples using TARP-4 multi-tumor tissue microarray. Virchows Arch 2003;443:122-32.

71. Vakonaki E, Soulitzis N, Sifakis S, Papadogianni D, Koutroulakis D, Spandidos DA. Overexpression and ratio disruption of DeltaNp63 and TAp63 isoform equilibrium in endometrial adenocarcinoma: Correlation with obesity, menopause, and grade I/II tumors. J Cancer Res Clin 2012;138: 1271-8.

72. Cui R, He J, Mei R, de Fromentel CC, Martel-Planche G, Taniere P, et al. Expression of p53, p63, and p73 isoforms in squamous cell carcinoma and adenocarcinoma of esophagus. Biochem Biophys Res Commun 2005;336:339-45.

73. Koga F, Kawakami S, Fujii Y, Saito K, Ohtsuka Y, Iwai A, et al. Impaired p63 expression associates with poor prognosis and uroplakin III expression in invasive urothelial carcinoma of the bladder. Clin Cancer Res 2003;9:5501-7.

74. Barbieri CE, Tang LJ, Brown KA, Pietenpol JA. Loss of p63 leads to increased cell migration and up-regulation of genes involved in invasion and metastasis. Cancer Res 2006;66:7589-97.

75. Yao Y, Bellon M, Shelton S, Nicot C. Tumor suppressors p53, p63TAalpha, p63TAy, p73alpha and p73beta use distinct pathways to repress telomerase expression. J Biol Chem 2012;287:20737-47.

76. Guo X, Keyes WM, Papazoglu C, Zuber J, Li W, Lowe SW, et al. TAp63 induces senescence and suppresses tumorigenesis in vivo. Nat Cell Biol 2009;11:1451-7.

77. Senoo M, Matsumura Y, Habu S. TAp63gamma (p51A) and dNp63alpha (p73L), two major isoforms of the p63 gene, exert opposite effects on the vascular endothelial growth factor (VEGF) gene expression. Oncogene 2002;21:2455-65.

78. Patturajan M, Nomoto S, Sommer M, Fomenkov A, Hibi K, Zangen $\mathrm{R}$, et al. DeltaNp63 induces beta-catenin nuclear accumulation and signaling. Cancer Cell 2002;1:369-79.

79. Hildesheim J, Belova GI, Tyner SD, Zhou X, Vardanian L, Fornace AJ, Jr. Gadd45a regulates matrix metalloproteinases by suppressing DeltaNp63alpha and beta-catenin via p38 MAP kinase and APC complex activation. Oncogene 2004;23:1829-37.

80. Chiang CT, Chu WK, Chow SE, Chen JK. Overexpression of delta Np63 in a human nasopharyngeal carcinoma cell line downregulates CKIs and enhances cell proliferation. J Cell Physiol 2009;219:117-22.

81. Yao JY, Pao CC, Chen JK. Transcriptional activity of TAp63 promoter is regulated by c-jun. J Cell Physiol 2010;225:898-904.

82. Yao JY, Chen JK. TAp63 plays compensatory roles in p53-deficient cancer cells under genotoxic stress. Biochem Biophys Res Commun 2010;403:310-5

83. Koster MI, Lu SL, White LD, Wang XJ, Roop DR. Reactivation of developmentally expressed p63 isoforms predisposes to tumor development and progression. Cancer Res 2006;66:3981-6.

84. Yen CC, Chen YJ, Pan CC, Lu KH, Chen PC, Hsia JY, et al. Copy number changes of target genes in chromosome 3q25.3-qter of esophageal squamous cell carcinoma: TP63 is amplified in early carcinogenesis but down-regulated as disease progressed. World J Gastroenterol 2005;11:1267-72. 